\title{
Clinical significance of midkine expression in sporadic desmoid tumors
}

\author{
HEE SUNG KIM ${ }^{1}$, JIN KIM ${ }^{2}$, KYUNG HAN NAM ${ }^{3}$ and WOO HO KIM ${ }^{2,4}$ \\ ${ }^{1}$ Department of Pathology, College of Medicine, Chung-Ang University, Seoul 156-755; \\ ${ }^{2}$ Cancer Research Institute, College of Medicine, Seoul National University, Seoul 110-799; \\ ${ }^{3}$ Department of Pathology, Haeundae Paik Hospital, Inje University College of Medicine, Busan 612-896; \\ ${ }^{4}$ Department of Pathology, College of Medicine, Seoul National University, Seoul 110-799, Republic of Korea
}

Received February 24, 2015; Accepted December 23, 2015

DOI: $10.3892 / \mathrm{ol} .2016 .4129$

\begin{abstract}
The aim of the present study was to identify the prognostic factors for the propensity for recurrence in sporadic desmoid tumors. The catenin (cadherin-associated protein) $\beta 1$ (CTNNB1) genotypes and expression of Wnt pathway proteins and midkine (also termed neurite growth-promoting factor 2) were investigated in 159 patients with sporadic desmoid tumors. Formalin-fixed paraffin-embedded tissues of the surgically resected desmoid tumors were examined by direct sequencing of CTNNB1 exon 3, and immunostained for the expression of $\beta$-catenin, T-cell factor 4 (TCF-4), phosphorylated protein kinase $\mathrm{B}(\mathrm{pAkt})$, midkine and menin using a tissue microarray method. Among the samples, $70 \%(111 / 159)$ exhibited point mutations of the CTNNB1 gene, including T41A (56\%), S45F (8\%), S45P (2\%), S45N (2\%) and T42A (1\%). In addition, 100, 57, 24, 15 and $92 \%$ of the tumors expressed $\beta$-catenin, TCF-4, midkine, pAkt and menin, respectively. Positive midkine expression was significantly associated with the recurrence of tumors $(\mathrm{P}=0.001)$. The multivariate analysis of recurrence demonstrated that an extra-abdominal tumor site [hazard ratio (HR), 2.625; $\mathrm{P}=0.001$ ] and midkine expression (HR, 2.077; $\mathrm{P}<0.009)$ were independent prognostic factors of tumor recurrence. In conclusion, the present results suggest that the tumor site and midkine expression may be predictive markers for the recurrence of sporadic desmoid tumors.
\end{abstract}

\section{Introduction}

The incidence rate of sporadic desmoid tumors is 2-4 individuals per million (1). Desmoid tumors originate from clonal fibroblastic proliferation with infiltrative growth and an inability to metastasize (2). The standard treatment

Correspondence to: Professor Woo Ho Kim, Department of Pathology, College of Medicine, Seoul National University, 28 Yeongeon-dong, Seoul 110-799, Republic of Korea

E-mail: woohokim@snu.ac.kr

Key words: midkine, CTNNB1, desmoid tumor, recurrence regimen consists of complete surgical resection, followed by anti-inflammatory therapy, hormonal blockade and cytotoxic chemotherapy in certain patients (3). The predominant obstacle in the management of desmoid tumors is the high propensity for local recurrence. Major retrospective studies report that the rate of recurrence is between 20 and $60 \%$ at 5 years, even following the complete ablation of the tumor $(4,5)$. Clinical characteristics, including the tumor site (such as the trunk) (4), a younger age (6) and the surgical margin (7), are associated with the risk of local recurrence of desmoid tumors.

Mutations in the adenomatous polyposis coli $(A P C)$ or catenin (cadherin-associated protein) $\beta 1$ (CTNNB1; $\beta$-catenin) genes have been identified in $89 \%$ of sporadic desmoid tumors and also in tumors that occur in association with familial adenomatous polyposis (2). In normal cells, the APC protein directly binds to free $\beta$-catenin and promotes its phosphorylation by glycogen synthase kinase- $3 \beta$ (GSK-3 $\beta$ ); this targets $\beta$-catenin for degradation via the ubiquitin-proteasome pathway (2). However, mutations in APC or $\beta$-catenin, and particularly in the GSK-3 $\beta$ phosphorylation sites, inhibit the binding of APC to $\beta$-catenin, leading to the stabilization of $\beta$-catenin, which accumulates in the cytoplasm and nucleus of the cell (6). Within the nucleus, $\beta$-catenin binds directly to the T-cell factor/lymphoid enhancer factor (TCF/LEF) group of DNA binding transcription factors and stimulates the transcription of its target genes (2). The three most common somatic $\beta$-catenin point mutations are located in codons 41 and 45 of exon 3. Previous studies have suggested that the molecular profile of $\beta$-catenin may be an important biological predictor of tumor recurrence; for example, the $\mathrm{S} 45 \mathrm{~F}$ mutation may be associated with the risk of desmoid tumor recurrence $(6,8)$.

Midkine, also termed neurite growth-promoting factor 2, is a heparin-binding growth factor that is involved in various cellular processes, including proliferation, survival and migration (9). Numerous cell-surface receptors have been identified to account for the multiple biological activities of midkine, including ALK, LRP1 and integrin (9). The human midkine gene maps to chromosome 11p11.2 (9). The truncated form of midkine is observed in several types of malignancies, including gastric and breast cancer, pancreatic carcinoma and Wilms' tumors (9). In addition, midkine was demonstrated to 
be commonly expressed in a large cohort of human desmoid tumor samples, and its increased expression was significantly associated with the risk of tumor recurrence (3). Menin, which is encoded by the multiple endocrine neoplasia type 1 gene, is a tumor suppressor and transcriptional regulator, and promotes the activity of the Wnt signaling pathway (10). Menin has been hypothesized to interact with $\beta$-catenin and promote its translocation between the nucleus and the cytoplasm (10).

The present study performed direct sequencing of the CTNNB1 gene and immunohistochemistry for the expression of midkine, $\beta$-catenin, TCF-4 and menin in resected desmoid tumor samples to assess the predictive value of these factors in the risk of tumor recurrence.

\section{Materials and methods}

Patients and tumor samples. A total of 159 resected sporadic desmoid tumors from initial surgeries of 159 patients were used in the present study. They were obtained between January 1990 and December 2009 at the Department of Pathology, Seoul National University Hospital (Seoul, South Korea). The anatomical sites were classified as being superficial (fascial), extra-abdominal, abdominal or intra-abdominal (11).

Only samples with confirmed desmoid tumor histology and an adequate amount of tissue for analysis were analyzed in the present study. The time to recurrence was calculated as the time between the initial surgery and the first tumor recurrence. Postoperative adjuvant therapy, radiotherapy, chemotherapy or combined radio- and chemotherapy were administered in 38, 12,7 and 4 patients, respectively. The chemotherapy regimens consisted of methotrexate, vinblastine, Glivec ${ }^{\circledR}$, sulindac, monosodium glutamate or tamoxifen. Detailed information, including demographics, therapeutic regimens, histopathological findings and clinical outcomes, were retrieved from the medical records of patients, pathology results and the database of the Ministry of Security and Public Administration, South Korean Government. The data retrieved comprised the patient gender, anatomical sites of tumors, tumor sizes, date of surgery, surgical margin, other treatments received following surgery, date of recurrence, treatment for recurrence, date of the last follow-up, status at the last follow-up and patient survival information.

The present study was approved by the Institutional Review Board of Seoul National University Hospital (approval no. H-1209-068-427).

Mutational analysis. For the extraction of genomic DNA, the lesion region was marked on a hematoxylin and eosin-stained slide by a pathologist. DNA was extracted from the formalin-fixed paraffin embedded blocks that contained $\geq 70 \%$ tumor content. Nested polymerase chain reaction was performed using the following primers for CTNNB1 exon 3 (cDNA NM_001904): Round 1 forward, 5'-ATGGAGTTG GACATGGCCAT-3' and reverse, 5'-CCTGAGGAAGAGGAT GTGGA-3'; and round 2 forward, 5'-CTGGCAGCAACAGTC TTACC-3' and reverse, 5'-CACTCA AGAACAAGTAG-3' (Macrogen, Seoul, Korea). For the first polymerase chain reaction (PCR), $200 \mathrm{ng}$ of the purified DNA, 10 pmol of either forward or reverse primer and Premix Ex Taq (Takara Bio
Inc., Otsu, Japan) was made up to a final volume of $20 \mu \mathrm{l}$ using distilled water for the PCR, which underwent 35 cycles at $95^{\circ} \mathrm{C}$ for $30 \mathrm{sec}, 58^{\circ} \mathrm{C}$ for $30 \mathrm{sec}$ and $72^{\circ} \mathrm{C}$ for $1 \mathrm{~min}$. A second PCR (nested PCR) was performed with the same protocol as the first PCR using the diluted (1:50) product of the first PCR. The amplified product was a 172-bp fragment, which was purified using the QIAamp DNA Mini kit (Qiagen GmbH, Hilden, Germany). Direct sequencing was performed using the forward, 5'-ATGGAGTTGGACATGGCCAT-3' and reverse, 5'-CACTCAAGAACAAGTAG-3' primers (Macrogen, Seoul, Korea), and the Applied Biosystems PRISM 3100 Genetic Analyzer (Thermo Fisher Scientific, Inc., Waltham, MA, USA). A negative control was performed by replacing the purified DNA with distilled water.

Immunohistochemistry. Tissue array sections of $4-\mu \mathrm{m}$ thickness were deparaffinized and rehydrated in graded alcohol. Antigen retrieval was achieved by pressure-cooking the slides in $0.01 \mathrm{~mol} / 1$ citrate buffer for $5 \mathrm{~min}$. The following primary antibodies were used: Polyclonal mouse anti-human $\beta$-catenin (dilution, 1:800; catalog no. 610153; Transduction Laboratories $^{\mathrm{TM}}$; BD Biosciences, Franklin Lakes, NJ, USA); monoclonal mouse anti-human TCF-4 (dilution, 1:100; clone, 6H5-3; catalog no. 05-511; Upstate Biotechnology, Inc., Lake Placid, NY, USA); monoclonal rabbit anti-human Akt 1 (phospho S473) (dilution, 1:100; catalog no. 2118-1; Epitomics, Burlingame, CA, USA); polyclonal rabbit anti-human midkine (dilution, 1:200; catalog no. 1937-1; Abcam, Cambridge, MA, USA); and monoclonal rabbit anti-human menin (dilution, 1:200; catalog no. 2817-1; Epitomics). Immunohistochemistry was performed and visualized using Bond-MAX (Leica Microsystems, Wetzlar, Germany) and Bond Polymer Refine Detection (Leica Biosystems, Newcastle, UK), respectively. Nuclear staining was considered to indicate expression of $\beta$-catenin, and tumor samples with $>10 \%$ cells expressing $\beta$-catenin were recorded as positive. The intensity of $\beta$-catenin staining was recorded as mild, moderate or strong. Midkine immunostaining was scored by intensity ( 0 , none; 1 , low; 2 , moderate/strong) and the percentage of positively-stained cells, and samples were regarded as positive if they met the following criteria: $>10 \%$ of cells and an intensity of 2 or 3; or $>50 \%$ of cells stained and an intensity of 1 . A sample was considered TCF-4-positive if $>30 \%$ of the cells were stained. Cytoplasmic pAkt immunostaining was considered to indicate positive pAkt expression. Negative menin expression for a sample was noted when $>90 \%$ of the cells did not exhibit staining in the nuclei.

Statistical analysis. SPSS version 20 software (IBM SPSS, Armonk, NY, USA) was used for statistical analysis. $\chi^{2}$ test and Cox regression analysis were used. All P-values were two-tailed. $\mathrm{P}<0.05$ was considered to indicate a statistically significant difference.

\section{Results}

Clinicopathological profiles of sporadic desmoid tumors. The present study evaluated the prevalence of CTNNB1 mutations in 159 patients with sporadic desmoid tumors. The patients consisted of 77 men $(48.4 \%)$ and 82 women $(51.6 \%)$. The 
Table I. Association between clinicopathological characteristics and tumor recurrence in patients with sporadic desmoid tumors.

\begin{tabular}{|c|c|c|c|c|}
\hline Variable & $\begin{array}{l}\text { Total, } \\
\mathrm{n}(\%)\end{array}$ & $\begin{array}{c}\text { Recurrence, } \\
\mathrm{n}(\%)\end{array}$ & $\begin{array}{c}\text { No recurrence, } \\
\mathrm{n}(\%)\end{array}$ & P-value \\
\hline Total patients & $157(100.0)$ & $67(42.7)$ & $90(57.3)$ & \\
\hline Gender & & & & 0.016 \\
\hline Female & $81(51.6)$ & $42(51.9)$ & $39(48.1)$ & \\
\hline Male & $76(48.4)$ & $25(32.9)$ & $51(67.1)$ & \\
\hline Age, years & & & & 0.002 \\
\hline$<30$ & 47 (29.9) & $29(61.7)$ & $18(38.3)$ & \\
\hline$\geq 30$ & $110(70.1)$ & $38(34.5)$ & $72(65.5)$ & \\
\hline Tumor size, $\mathrm{cm}$ & & & & 0.983 \\
\hline$<6.0$ & $95(61.3)$ & $41(43.2)$ & $54(56.8)$ & \\
\hline$\geq 6.0$ & $60(38.7)$ & $26(43.3)$ & $34(56.7)$ & \\
\hline Site & & & & $<0.001$ \\
\hline Superficial (fascial) & $45(28.7)$ & $12(26.7)$ & $33(73.3)$ & \\
\hline Extra-abdominal & $69(43.9)$ & $45(65.2)$ & $24(34.8)$ & \\
\hline Abdominal & $24(15.3)$ & $5(20.8)$ & $19(79.2)$ & \\
\hline Intra-abdominal & $19(12.1)$ & $5(26.3)$ & $14(73.7)$ & \\
\hline Growth & & & & 0.361 \\
\hline Nodular & 39 (26.9) & $14(35.9)$ & $25(64.1)$ & \\
\hline Infiltrative & $106(73.1)$ & $47(44.3)$ & $59(55.7)$ & \\
\hline Resection margin & & & & 0.594 \\
\hline Not involved & $65(53.7)$ & $31(47.7)$ & $34(52.3)$ & \\
\hline Involved & $56(46.3)$ & $24(42.9)$ & $32(57.1)$ & \\
\hline CTNNB1 & & & & 0.116 \\
\hline Wild-type & $48(30.6)$ & $16(33.3)$ & $32(66.7)$ & \\
\hline Mutation & $109(69.4)$ & $51(46.8)$ & $58(53.2)$ & \\
\hline CTNNB1 & & & & 0.113 \\
\hline Wild-type & $48(30.6)$ & $16(33.3)$ & $32(66.7)$ & \\
\hline T41 mutation & $88(56.1)$ & $44(50.0)$ & $44(50.0)$ & \\
\hline S45 mutation & $18(11.5)$ & 7 (38.9) & $11(61.1)$ & \\
\hline Other mutation & $3(1.9)$ & $0(0.0)$ & $3(100.0)$ & \\
\hline$\beta$-catenin intensity & & & & 0.876 \\
\hline Weak & $60(40.8)$ & $26(43.3)$ & $34(56.7)$ & \\
\hline Moderate & $64(43.5)$ & $29(45.3)$ & $35(54.7)$ & \\
\hline Strong & $23(15.6)$ & $9(39.1)$ & $14(60.9)$ & \\
\hline TCF-4 & & & & 0.105 \\
\hline Negative & $63(42.6)$ & $22(34.9)$ & $41(65.1)$ & \\
\hline Positive & $85(57.4)$ & $41(48.2)$ & $44(51.8)$ & \\
\hline Menin & & & & 0.696 \\
\hline Negative & $11(7.6)$ & $4(36.4)$ & 7 (63.6) & \\
\hline Positive & $132(91.7)$ & $56(42.4)$ & $76(57.6)$ & \\
\hline pAkt & & & & 0.857 \\
\hline Negative & $121(84.6)$ & $52(43.0)$ & $69(57.0)$ & \\
\hline Positive & $22(15.4)$ & $9(40.9)$ & $13(59.1)$ & \\
\hline Midkine & & & & 0.007 \\
\hline Negative & $111(76.0)$ & $41(36.9)$ & $70(63.1)$ & \\
\hline Positive & $35(24.0)$ & $22(62.9)$ & $13(37.1)$ & \\
\hline
\end{tabular}
(cadherin-associated protein) $\beta 1$ gene; TCF-4, T cell-factor 4; pAkt, phosphorylated protein kinase B. 
Table II. Association between clinicopathological characteristics and CTNNB1 mutations in patients with sporadic desmoid tumors.

\begin{tabular}{|c|c|c|c|c|c|c|c|c|}
\hline \multirow[b]{2}{*}{ Variable } & \multirow[b]{2}{*}{$\begin{array}{l}\text { Total, } \\
\mathrm{n}(\%)\end{array}$} & \multicolumn{3}{|c|}{ CTNNB1 } & \multicolumn{4}{|c|}{ CTNNB1 mutation } \\
\hline & & $\begin{array}{c}\text { Wild-type, } \\
\text { n (\%) }\end{array}$ & $\begin{array}{c}\text { Mutation, } \\
\text { n }(\%)\end{array}$ & P-value ${ }^{a}$ & $\begin{array}{l}\mathrm{T} 41, \\
\mathrm{n}(\%)\end{array}$ & $\begin{array}{l}\mathrm{S} 45, \\
\mathrm{n}(\%)\end{array}$ & $\begin{array}{l}\text { Other, } \\
\mathrm{n}(\%)\end{array}$ & $\mathrm{P}$-value ${ }^{\mathrm{b}}$ \\
\hline Total & $159(100.0)$ & $48(30.2)$ & $111(69.8)$ & & $89(56.0)$ & $19(11.9)$ & $3(1.9)$ & \\
\hline Gender & & & & 0.100 & & & & 0.211 \\
\hline Female & $82(51.6)$ & $20(24.4)$ & $62(75.6)$ & & $52(63.4)$ & $8(9.8)$ & $2(2.4)$ & \\
\hline Male & $77(48.4)$ & $28(36.4)$ & $49(63.6)$ & & $37(48.1)$ & $11(14.3)$ & $1(1.3)$ & \\
\hline Age, years & & & & 0.227 & & & & 0.158 \\
\hline$<30$ & $47(29.6)$ & $11(23.4)$ & $36(76.6)$ & & $27(57.4)$ & $9(19.1)$ & $0(0.0)$ & \\
\hline$\geq 30$ & $112(70.4)$ & $37(33.0)$ & $75(67.0)$ & & $62(55.4)$ & $10(8.9)$ & $3(2.7)$ & \\
\hline Tumor size, $\mathrm{cm}$ & & & & 0.060 & & & & 0.407 \\
\hline$<6.0$ & $96(61.1)$ & $34(35.4)$ & $62(64.6)$ & & $52(54.2)$ & $8(8.3)$ & $2(2.1)$ & \\
\hline$\geq 6.0$ & $61(38.9)$ & $13(21.3)$ & $48(78.7)$ & & $36(59.0)$ & $11(18.0)$ & $1(1.6)$ & \\
\hline Site & & & & 0.014 & & & & 0.005 \\
\hline Superficial (fascial) & $45(28.3)$ & $22(48.9)$ & $23(51.1)$ & & $21(46.7)$ & $1(2.2)$ & $1(2.2)$ & \\
\hline Extra-abdominal & $71(44.7)$ & $16(22.5)$ & $55(77.5)$ & & $43(60.6)$ & $12(16.9)$ & $0(0.0)$ & \\
\hline Abdominal & $24(15.1)$ & $5(20.8)$ & $19(79.2)$ & & $12(50.0)$ & $5(20.8)$ & $2(8.3)$ & \\
\hline Intra-abdominal & $19(11.9)$ & $5(26.3)$ & $14(73.7)$ & & $13(68.4)$ & $1(5.3)$ & $0(0.0)$ & \\
\hline Growth & & & & 0.563 & & & & 0.619 \\
\hline Nodular & $39(26.5)$ & $10(25.6)$ & $29(74.4)$ & & $21(53.8)$ & 7 (17.9) & $1(2.6)$ & \\
\hline Infiltrative & $108(73.5)$ & $33(30.6)$ & $75(69.4)$ & & $62(57.4)$ & $11(10.2)$ & $2(1.9)$ & \\
\hline Resection margin & & & & 0.358 & & & & 0.68 \\
\hline Not involved & $65(53.7)$ & $16(24.6)$ & $49(75.4)$ & & $39(60.0)$ & $9(13.8)$ & $1(1.5)$ & \\
\hline Involved & $56(46.3)$ & $18(32.1)$ & $38(67.9)$ & & $29(51.8)$ & $7(12.5)$ & $2(3.6)$ & \\
\hline$\beta$-catenin intensity & & & & 0.063 & & & & 0.184 \\
\hline Weak & $60(40.3)$ & $25(41.7)$ & $35(58.3)$ & & $29(48.3)$ & $6(10.0)$ & $0(0.0)$ & \\
\hline Moderate & $66(44.3)$ & $18(27.3)$ & $48(72.7)$ & & $35(53.0)$ & $11(16.7)$ & $2(3.0)$ & \\
\hline Strong & $23(15.4)$ & $4(17.4)$ & $19(82.6)$ & & $16(69.6)$ & $2(8.7)$ & $1(4.3)$ & \\
\hline TCF-4 & & & & 0.245 & & & & 0.589 \\
\hline Negative & $63(42.0)$ & $23(36.5)$ & $40(63.5)$ & & $33(52.4)$ & $6(9.5)$ & $1(1.6)$ & \\
\hline Positive & $87(58.0)$ & $24(27.6)$ & $63(72.4)$ & & $48(55.2)$ & $13(14.9)$ & $2(2.3)$ & \\
\hline Menin & & & & 0.731 & & & & 0.924 \\
\hline Negative & $11(7.6)$ & $4(36.4)$ & $7(63.6)$ & & $6(54.5)$ & $1(9.1)$ & $0(0.0)$ & \\
\hline Positive & $134(92.4)$ & $42(31.3)$ & $92(68.7)$ & & $71(53.0)$ & $18(13.4)$ & $3(2.2)$ & \\
\hline pAkt & & & & 0.360 & & & & 0.663 \\
\hline Negative & $123(84.8)$ & $40(32.5)$ & $83(67.5)$ & & $64(52.0)$ & $16(13.0)$ & $3(2.4)$ & \\
\hline Positive & $22(15.2)$ & $5(22.7)$ & $17(77.3)$ & & $14(63.6)$ & $3(13.6)$ & $0(0.0)$ & \\
\hline Midkine & & & & 0.024 & & & & 0.131 \\
\hline Negative & $111(75.0)$ & $40(36.0)$ & $71(64.0)$ & & $57(51.4)$ & $12(10.8)$ & $2(1.8)$ & \\
\hline Positive & $37(25.0)$ & $6(16.2)$ & $31(83.8)$ & & $23(62.2)$ & 7 (18.9) & $1(2.7)$ & \\
\hline
\end{tabular}

Certain categories have fewer than 159 patients or $100 \%$ in total, as cases with unavailable information were not included. ${ }^{a}$ Wild-type vs. mutation; bamong mutation types. CTNNB1, catenin (cadherin-associated protein) $\beta 1$ gene; TCF- 4 , T cell-factor 4 ; pAkt, phosphorylated protein kinase B.

average age of the patients was 41.2 years (range, 7-83 years). In total, $28.3 \%$ of the desmoid tumors were superficial (fascial; 45 patients), $44.7 \%$ were extra-abdominal (71 patients), $15.1 \%$ were abdominal (24 patients) and $11.9 \%$ were intra-abdominal (19 patients). The association between clinicopathological characteristics and tumor recurrence was analyzed. Tumor recurrence was significantly associated with a female gender $(\mathrm{P}=0.016)$, younger age $(<30$ years; $\mathrm{P}=0.002)$, extra-abdominal tumor site $(\mathrm{P}<0.001)$ and expression of midkine $(\mathrm{P}=0.007)$ (Table I). 
A

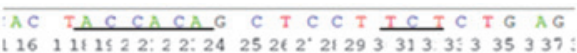
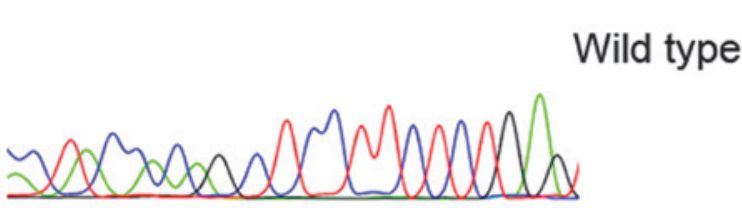

C

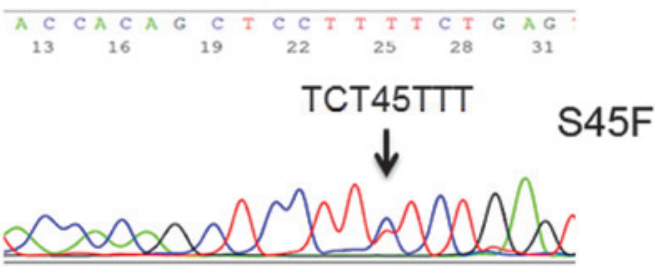

B

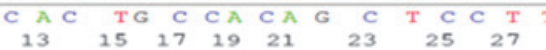

ACC $41 \mathrm{GCC}$

T41A

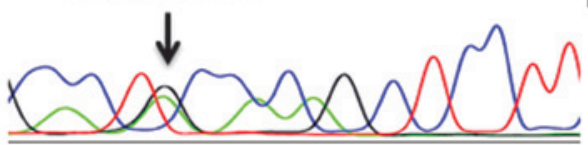

$\mathbf{D}$

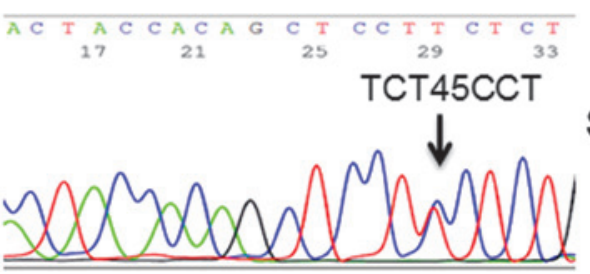

Figure 1. Catenin (cadherin associated protein) $\beta 1$ mutations in samples of sporadic desmoids tumors. (A) Wild-type, (B) T41A mutation, (C) S45F mutation and (D) S45P mutation.

A

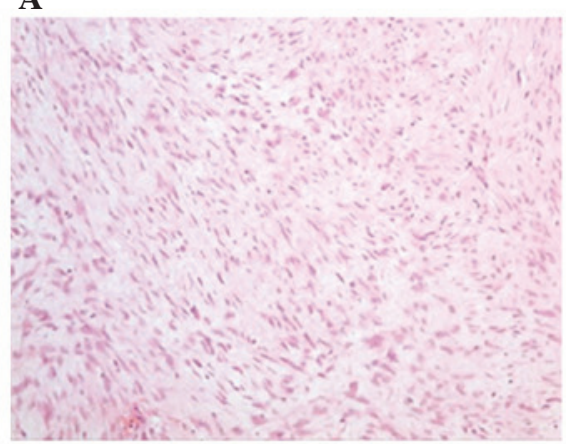

\section{D}

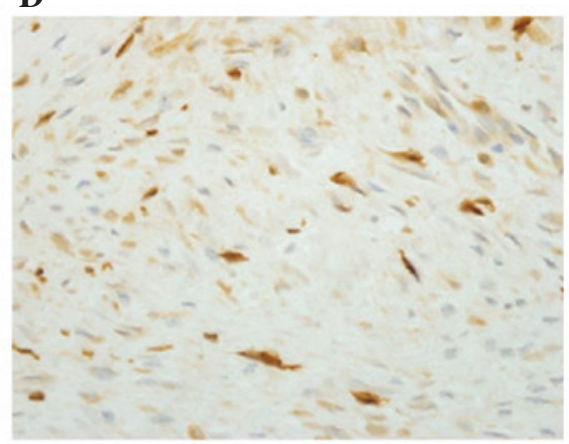

B

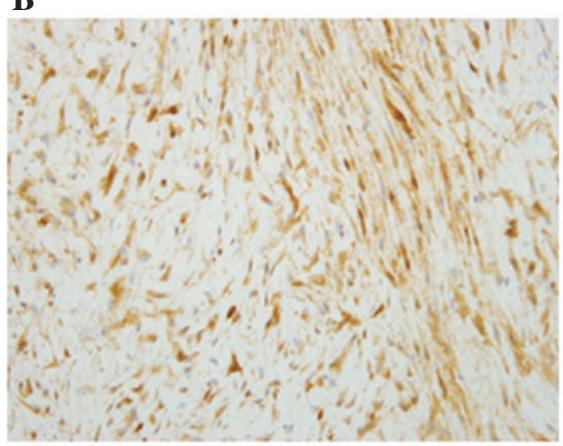

$\mathbf{E}$

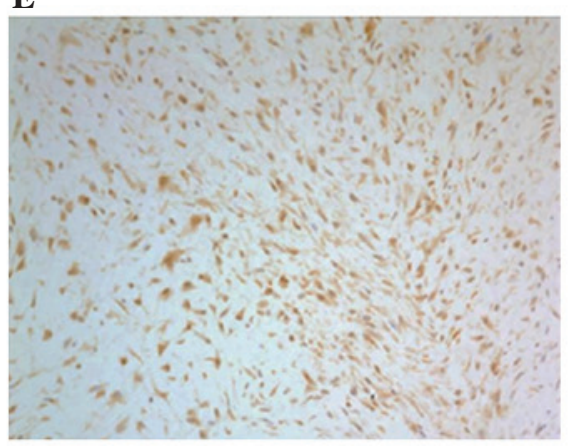

$\mathbf{C}$

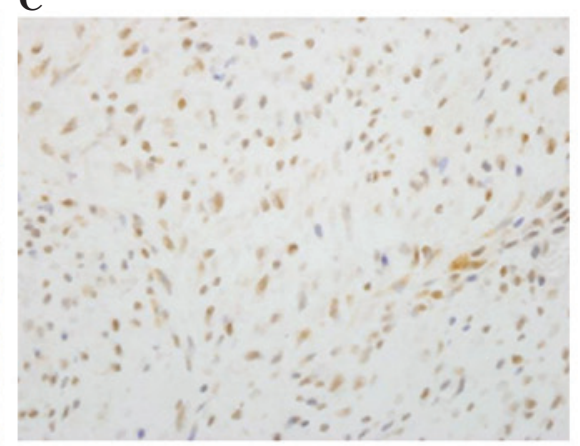

$\mathbf{F}$

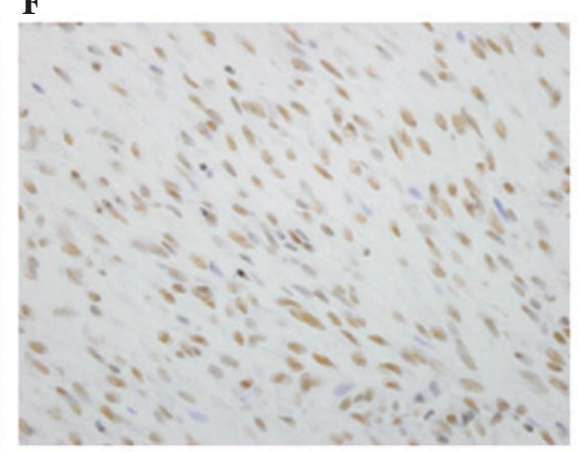

Figure 2. Immunohistochemical staining of $\beta$-catenin, TCF-4, midkine, pAkt, and menin in sporadic desmoid tumors. (A) Hematoxylin and eosin-stained section of a sporadic desmoid tumor, (B) $\beta$-catenin staining, (C) TCF-4 staining, (D) midkine staining, (E) pAkt staining and (F) menin staining. Magnification, x200. TCF-4; T cell-factor 4; pAkt, phosphorylated protein kinase B.

CTNNB1 genotype in sporadic desmoid tumors. Mutations in CTNNB1 were detected in $69.8 \%(111 / 159)$ of the tumors. Point mutations were identified in 4 codons, corresponding to T41, S45, T42 and G48 amino acids (Fig. 1). The replacement of threonine by alanine at codon 41 (p.T41A) was observed in $56 \%$ of the tumors $(n=89)$. At codon 45 , replacement of serine by phenylalanine (p.S45F), serine by proline (p.S45P) or serine by asparagine (p.S45N) was identified in $8.2 \%(13 / 159)$, $1.9 \%(3 / 159)$ and $1.9 \%$ (3/159) of the tumors, respectively. A point mutation in T42, resulting in the replacement of threonine by alanine (p.T42A) was observed in 1 tumor $(0.6 \%)$. A silent mutation in $\mathrm{G} 48$, consisting of a codon alteration from GGT to GGC, was observed in 1 tumor $(0.6 \%)$. The intensity of $\beta$-catenin expression was not associated with the presence of the CTNNB1 mutation or genotype (Table II).

Immunohistochemical staining for midkine and Wnt pathway proteins. All successful tumor samples expressed $\beta$-catenin [weak intensity, 40.3\% (60/149); moderate to strong intensity, $59.7 \%$ (89/149)]. In certain cases, immunostaining failed and these results were excluded. Therefore, $58.0 \%(87 / 150)$ of the tumors expressed TCF-4, 92.4\% (134/145) expressed menin, $15.2 \%$ (22/145) expressed pAkt and 25.0\% (37/148) expressed midkine (Fig. 2). Positive expression of midkine was significantly associated with tumor recurrence $(\mathrm{P}=0.007)$. However, there was no significant association between tumor recurrence 
Table III. Multivariate Cox analysis of recurrence-free survival and overall survival time in patients with sporadic desmoid tumors.

\begin{tabular}{|c|c|c|c|c|}
\hline Variable & $\mathrm{n}$ & P-value & HR & $95 \% \mathrm{CI}$ \\
\hline Total & 145 & & & \\
\hline Age, years & & 0.064 & 1.644 & $0.972-2.781$ \\
\hline$\geq 30$ & 100 & & & \\
\hline$<30$ & 45 & & & \\
\hline Site & & 0.001 & 2.625 & $1.491-4.623$ \\
\hline Extra-abdominal & 66 & & & \\
\hline Other & 79 & & & \\
\hline CTNNB1 & & 0.517 & 1.229 & $0.659-2.289$ \\
\hline Mutation & 99 & & & \\
\hline Wild-type & 46 & & & \\
\hline Midkine expression & & 0.009 & 2.077 & $1.203-3.587$ \\
\hline Positive & 35 & & & \\
\hline Negative & 110 & & & \\
\hline
\end{tabular}

Only the 145 patients with available information regarding all 4 variables were included in the multivariate Cox analysis. HR, hazard ratio; CTNNB1, catenin (cadherin-associated protein) $\beta 1$ gene; CI, confidence interval.
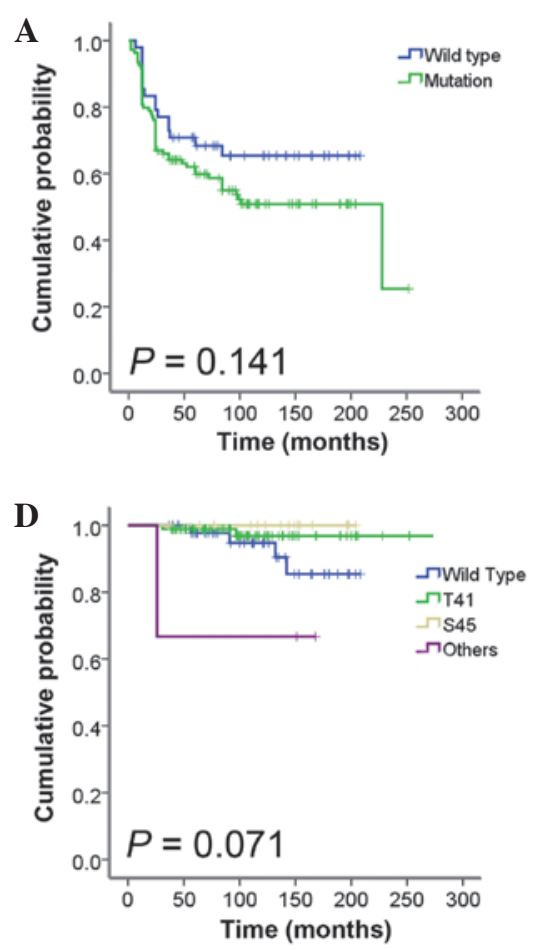
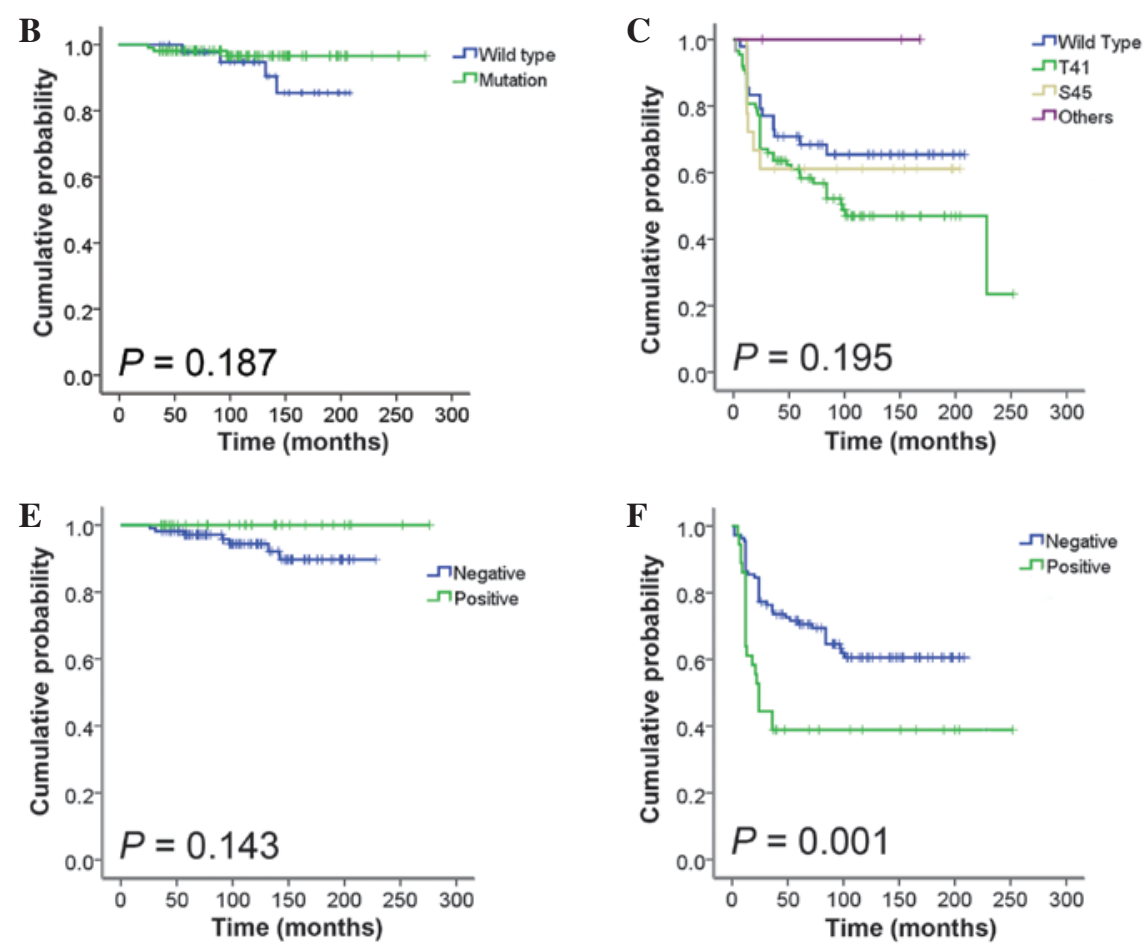

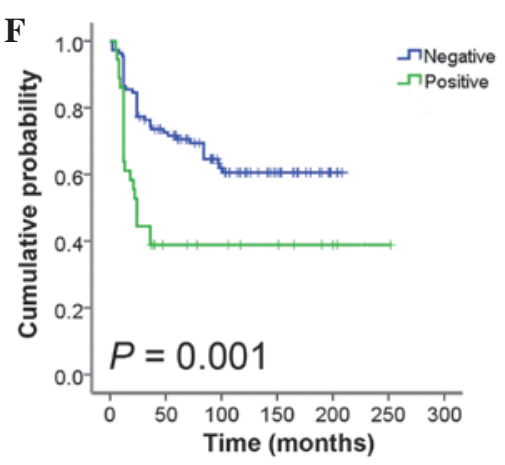

Figure 3. Kaplan-Meier analysis of RFS or OS time in patients with sporadic desmoid tumors. No significant association between (A and C) OS or (B and D) RFS time and the presence of catenin (cadherin-associated protein) $\beta 1$ mutations or genotypes were observed. (E and F) According to midkine protein expression, no significant difference was noted for (E) OS time. (F) Midkine positive desmoid tumors demonstrated a significantly shorter RFS time compared with desmoid tumors that did not express midkine. RFS, recurrence free survival; OS, overall survival.

and CTNNB1 mutations and TCF-4, menin and pAkt expression.

Analysis of recurrence-free survival (RFS) time. Kaplan-Meier analysis for RFS time demonstrated that midkine expression was significantly associated with a shorter RFS time $(\mathrm{P}=0.001$; Fig. 3). In the multivariate Cox regression analysis, four clinical characteristics (age, $\geq 30$ vs. $<30$ years; tumor site, extra-abdominal vs. others; CTNNB1 genotype, mutation vs. wild-type; midkine expression, positive vs. negative) were included as covariates. This revealed that an extra-abdominal tumor site [hazard ratio (HR), 2.625; $\mathrm{P}=0.001$ ] and positive midkine expression $(\mathrm{HR}, 2.077 ; \mathrm{P}=0.009)$ were independent predictors of RFS time (Table III). 


\section{Discussion}

The present study confirmed that positive midkine expression in sporadic desmoid tumors is significantly associated with tumor recurrence. In a previous target gene screening study for sporadic desmoid tumors, 98 genes were identified to be overexpressed. Among the genes containing a TCF/LEF consensus-binding site, midkine was demonstrated to have a significant association with tumor recurrence (3). Midkine binds with high affinity to the chondroitin sulfate portion of protein tyrosine phosphatase (PTP) $\zeta$, and to the cell-surface nucleolin receptor with low affinity. Following binding to its ligand, PTP $\zeta$ undergoes dimerization, which inactivates the phosphatase domain and leads to an increase in intracellular tyrosine phosphate. $\beta$-catenin has been identified as the substrate of PTP $\zeta$ (12).

The high expression of midkine in Wilms' tumors suggests that midkine is a target gene of Wilms' tumor 1 (WT1) (13). The wild-type WT1 gene is markedly overexpressed in $\beta$-catenin-mutant desmoid tumors. The Wnt signaling pathway interacts with WT1 in normal kidney development and commonly plays a role in the genesis of Wilms' tumors. WT1 overexpression is hypothesized to be involved in the association between the $\beta$-catenin mutation and midkine overexpression in sporadic desmoid tumors $(13,14)$.

The majority of sporadic desmoid tumors ( $85 \%)$ have mutations in the $\beta$-catenin gene CTNNB1, which is located on the short arm of chromosome 3 . In addition, frequent point mutations at codons 41 and 45 (T41A, S45F and S45P) have been identified in sporadic desmoid tumors $(6,7)$. A previous large series of sporadic desmoid tumors suggested that T41A is the most common mutation, and patients harboring $\mathrm{S} 45 \mathrm{~F}$ mutations are at an increased risk of tumor recurrence (6). This finding was also confirmed by a multicenter validation study (8). The CTNNB1 gene, which encodes a component of the Wnt signaling pathway, is hypothesized to cause dysregulation of proliferation and invasiveness in fibroblasts $(7,15,16)$.

In the present study, a mutation frequency of $70 \%$ was observed; these mutations occurred predominantly in T41 (T41A, 56\% of all patients) or S45 (12\%), whilst the remaining $2 \%$ harbored other mutations. Notably, compared with previous studies, the mutation rate in the present study was lower (70 vs. 83-87\%), the frequency of the T41 mutation was higher (56 vs. $35-50 \%$ ) and the frequency of the S45 mutation was lower (12 vs. $35-52 \%)(6,17,18)$.

Colombo et al (8) observed a specific association between the type of CTNNB1 mutation and the site of the origin of desmoid tumors; a predominance of the S45F mutation was observed in extremity desmoid tumors, indicating that the $\mathrm{S} 45 \mathrm{~F}$ mutation is associated with a poor outcome of patients. By contrast, the association between the type of CTNNBI mutation and the site of origin of the desmoid tumor differed in the present study; a higher frequency of the S45 mutation was identified in the extra-abdominal and abdominal sites compared with the superficial or intra-abdominal sites. The T41 mutation was more common in the intra-abdominal and head and neck fibromatoses. These results are supported by a previous study that demonstrated that the T41 mutation is more frequent in mesenteric fibromatoses (80.4\%) compared with the abdominal wall and extra-abdominal fibromatoses
(46.4\%) (19). In addition, the current study observed that there was no significant association between the CTNNB1 mutation and clinicopathological characteristics, which is supported by the results from a previous study (18).

It is possible that ethnic differences between Western and Asian countries affects the frequency of the mutations. Notably, two previous Japanese studies reported that the frequencies of CTNNB1 mutations in patients with sporadic desmoid tumors were $38.9 \%$ (7/18 patients) (20) and $52.4 \%$ (22/42 patients) (21). Independent multicenter studies with large cohorts of patients are required to further investigate these ethnic variations.

Occasionally, desmoid tumors are focally positive for nuclear $\beta$-catenin, and protein expression levels may vary within the tumor $(22,23)$. Therefore, $C T N N B 1$ genotyping may be beneficial in the differential diagnosis of desmoid tumors. However, we suggest that extensive statistical data and analysis are required for the clinical application of this genotyping (18).

In conclusion, the present study demonstrated that midkine-positivity in sporadic desmoid tumors is significantly associated with the risk of tumor recurrence. Therefore, midkine expression may be considered as a predictive marker for the recurrence of sporadic desmoid tumors, and may be useful for determining treatment regimens for patients.

\section{Acknowledgements}

The present study was supported by the Seoul National University Hospital Research Fund (grant no. 03-2012-0190).

\section{References}

1. Reitamo JJ, Häyry P, Nykyri E and Saxén E: The desmoid tumor. I. Incidence, sex-, age- and anatomical distribution in the Finnish population. Am J Clin Pathol 77: 665-673, 1982.

2. Alman BA, Li C, Pajerski ME, Diaz-Cano S and Wolfe HJ Increased beta-catenin protein and somatic APC mutations in sporadic aggressive fibromatoses (desmoid tumors). Am J Pathol 151: 329-334, 1997.

3. Colombo C, Creighton CJ, Ghadimi MP, Bolshakov S, Warneke CL, Zhang Y, Lusby K, Zhu S, Lazar AJ, West RB, et al: Increased midkine expression correlates with desmoid tumour recurrence: A potential biomarker and therapeutic target. J Pathol 225: 574-582, 2011.

4. Fiore M, Rimareix F, Mariani L, Domont J, Collini P, Le Péchoux C, Casali PG, Le Cesne A, Gronchi A and Bonvalot S: Desmoid-type fibromatosis: A front-line conservative approach to select patients for surgical treatment. Ann Surg Oncol 16: 2587-2593, 2009.

5. Ballo MT, Zagars GK, Pollack A, Pisters PW and Pollack RA: Desmoid tumor: Prognostic factors and outcome after surgery, radiation therapy, or combined surgery and radiation therapy. J Clin Oncol 17: 158-167, 1999.

6. Lazar AJ, Tuvin D, Hajibashi S, Habeeb S, Bolshakov S, Mayordomo-Aranda E, Warneke CL, Lopez-Terrada D, Pollock RE and Lev D: Specific mutations in the beta-catenin gene $(C T N N B 1)$ correlate with local recurrence in sporadic desmoid tumors. Am J Pathol 173: 1518-1527, 2008.

7. Lazar AJ, Hajibashi S and Lev D: Desmoid tumor: From surgical extirpation to molecular dissection. Curr Opin Oncol 21: 352-359, 2009.

8. Colombo C, Miceli R, Lazar AJ, Perrone F, Pollock RE, Le Cesne A, Hartgrink HH, Cleton-Jansen AM, Domont J, Bovée JV, et al: CTNNB1 45F mutation is a molecular prognosticator of increased postoperative primary desmoid tumor recurrence: An independent, multicenter validation study. Cancer 119: 3696-3702, 2013.

9. Sakamoto K and Kadomatsu K: Midkine in the pathology of cancer, neural disease, and inflammation. Pathol Int 62: 445-455, 2012. 
10. Cao Y, Liu R, Jiang X, Lu J, Jiang J, Zhang C, Li X and Ning G: Nuclear-cytoplasmic shuttling of menin regulates nuclear translocation of $\{$ beta\}-catenin. Mol Cell Biol 29: 5477-5487, 2009.

11. Weiss SW and Goldblum JR (eds): Fibromatoses. In: Enzinger and Weiss's Soft Tissue Tumors. Vol 1. 5th edition. Elsevier, Inc., Philadelphia, PA, p228, 2008.

12. Meng K, Rodriguez-Peña A, Dimitrov T, Chen W, Yamin M, Noda $\mathrm{M}$ and Deuel TF: Pleiotrophin signals increased tyrosine phosphorylation of beta beta-catenin through inactivation of the intrinsic catalytic activity of the receptor-type protein tyrosine phosphatase beta/zeta. Proc Natl Acad Sci USA 97: 2603-2608, 2000.

13. Amini Nik S, Hohenstein P, Jadidizadeh A, Van Dam K, Bastidas A, Berry RL, Patek CE, Van der Schueren B, Cassiman JJ and Tejpar S: Upregulation of Wilms' tumor gene 1 (WT1) in desmoid tumors. Int J Cancer 114: 202-208, 2005.

14. Adachi Y, Matsubara S, Pedraza C, Ozawa M, Tsutsui J, Takamatsu H, Noguchi H, Akiyama T and Muramatsu T: Midkine as a novel target gene for the Wilms' tumor suppressor gene (WT1). Oncogene 13: 2197-2203, 1996.

15. Mignemi NA, Itani DM, Fasig JH, Keedy VL, Hande KR, Whited BW, Homlar KC, Correa H, Coffin CM, Black JO, et al Signal transduction pathway analysis in desmoid-type fibromatosis: Transforming growth factor- $\beta, \mathrm{COX} 2$ and sex steroid receptors. Cancer Sci 103: 2173-2180, 2012.

16. Cheon S, Poon R, Yu C, Khoury M, Shenker R, Fish J and Alman BA: Prolonged beta-catenin stabilization and tcf-dependent transcriptional activation in hyperplastic cutaneous wounds. Lab Invest 85: 416-425, 2005.
17. Amary MF, Pauwels P, Meulemans E, Roemen GM, Islam L, Idowu B, Bousdras K, Diss TC, O'Donnell P and Flanagan AM: Detection of beta-catenin mutations in paraffin-embedded sporadic desmoid-type fibromatosis by mutation-specific restriction enzyme digestion (MSRED): An ancillary diagnostic tool. Am J Surg Pathol 31: 1299-1309, 2007.

18. Dômont J, Salas S, Lacroix L, Brouste V, Saulnier P, Terrier $\mathrm{P}$, Ranchère $\mathrm{D}$, Neuville $\mathrm{A}$, Leroux $\mathrm{A}$, Guillou L, et al: High frequency of $\beta$-catenin heterozygous mutations in extra-abdominal fibromatosis: A potential molecular tool for disease management. Br J Cancer 102: 1032-1036, 2010.

19. Huss S, Nehles J, Binot E, Wardelmann E, Mittler J, Kleine MA, Künstlinger H, Hartmann W, Hohenberger P, Merkelbach-Bruse S, et al: $\beta$-catenin (CTNNB1) mutations and clinicopathological features of mesenteric desmoid-type fibromatosis. Histopathology 62: 294-304, 2013.

20. Saito T, Oda Y, Tanaka K, Matsuda S, Tamiya S, Iwamoto Y and Tsuneyoshi M: Beta-catenin nuclear expression correlates with cyclin D1 overexpression in sporadic desmoid tumours. J Pathol 195: 222-228, 2001.

21. Tejpar S, Nollet F, Li C, Wunder JS, Michils G, dal Cin P, Van Cutsem E, Bapat B, van Roy F, Cassiman JJ and Alman BA: Predominance of beta-catenin mutations and beta-catenin dysregulation in sporadic aggressive fibromatosis (desmoid tumor). Oncogene 18: 6615-6620, 1999.

22. Coffin CM, Hornick JL, Zhou H and Fletcher CD: Gardner fibroma: A clinicopathologic and immunohistochemical analysis of 45 patients with 57 fibromas. Am J Surg Pathol 31: 410-416, 2007.

23. Montgomery E and Folpe AL: The diagnostic value of beta-catenin immunohistochemistry. Adv Anat Pathol 12: 350-356, 2005. 